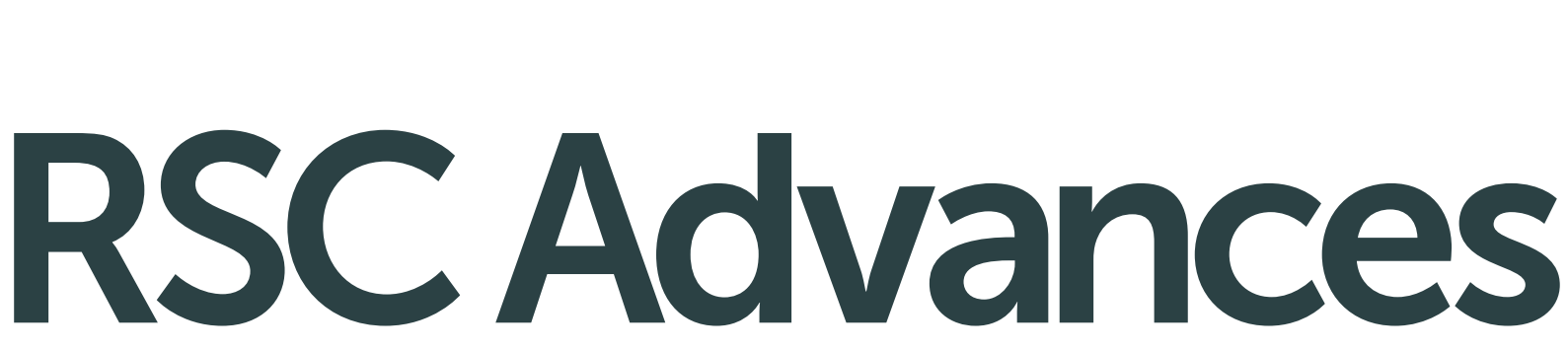

This article can be cited before page numbers have been issued, to do this please use: G. J. Maximo, M.

C. Costa, J. A.P. Coutinho and A. Meirelles, RSC Adv., 2014, DOI: 10.1039/C4RA02715A.

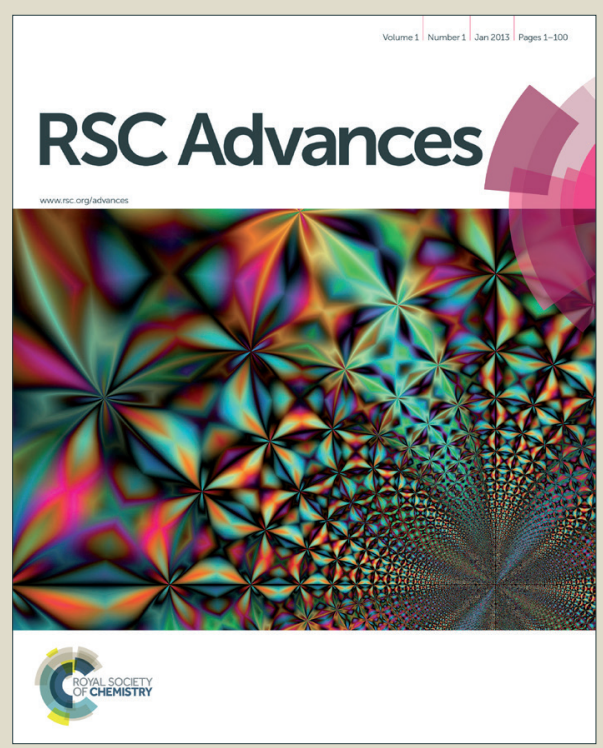

This is an Accepted Manuscript, which has been through the Royal Society of Chemistry peer review process and has been accepted for publication.

Accepted Manuscripts are published online shortly after acceptance, before technical editing, formatting and proof reading. Using this free service, authors can make their results available to the community, in citable form, before we publish the edited article. This Accepted Manuscript will be replaced by the edited, formatted and paginated article as soon as this is available.

You can find more information about Accepted Manuscripts in the Information for Authors.

Please note that technical editing may introduce minor changes to the text and/or graphics, which may alter content. The journal's standard Terms \& Conditions and the Ethical guidelines still apply. In no event shall the Royal Society of Chemistry be held responsible for any errors or omissions in this Accepted Manuscript or any consequences arising from the use of any information it contains. 


\title{
Trends and demands in solid-liquid equilibrium of lipidic mixtures
}

\author{
Guilherme J. Maximo, ${ }^{a, c}$ Mariana C. Costa,${ }^{b}$ João A. P. Coutinho, ${ }^{c}$ and Antonio J. A. Meirelles ${ }^{a}$ \\ Received (in $X X X, X X X)$ Xth $X X X X X X X X X 20 X X$, Accepted Xth $X X X X X X X X X 20 X X$ \\ DOI: $10.1039 / \mathbf{b 0 0 0 0 0 0 x}$
}

\begin{abstract}
${ }_{5}$ The production of fats and oils presents a remarkable impact in the economy, in particular in developing countries. In order to deal with the upcoming demands of the oil chemistry industry, the study of the solid-liquid equilibrium of fats and oils is highly relevant as it may support the development of new processes and products, as well as improve those already existent. However, the task is daunting because lipidic compounds present multiple solid phases leading to behaviors that deserve special attention. The

10 high complexity of these systems requires a particular effort for the experimental study and theoretical description of their phase behavior. This work is addressed at perspectives to better understand and overcome some of these issues.
\end{abstract}

\section{Introduction}

The study of the solid-liquid equilibrium (SLE) of lipidic 15 mixtures is a fundamental tool for the development and optimization of the processing of fatty based products. Fats and oils are remarkable suppliers of food, materials, chemicals and also energy. In this context, vegetable oils represented more than 150 milions of tons ${ }^{1}$ of produced and consumed material in 2012.

20 This information reveals the importance that fats and oils should have in the Research, Development and Innovation (RD\&I) policy agenda especially in the context of developing countries, that attend for more than $70 \%$ of this amount. Finding alternatives for adding value to a long list of products and 25 byproducts extracted from crops, fruits or seeds, as proposed in the biorefinary concept, is a task that is gaining a growing attention. A fats and oils biorefinary involves all the manufacturing steps concerning the extraction of the oil from the feedstock and production of any derived fatty based biochemical

${ }_{30}{ }^{2,3}$. It means that numerous separation and purification processes such as extraction, refining, crystallization or fractionation as well as products such as chocolate, butters, dressings, spreads, cosmetic creams, medicines or biofuels with specific physicochemical properties shall be then correctly designed and 35 this can only be attended by a reliable evaluation of the phase transition phenomena involving the compounds presents in fats and oils and their derivatives, and in particular their solid-liquid transitions (Figure 1).

The melting process of lipidic compounds is highly complex 40 when compared with other phase changes. This complexity is especially due to the inherent ability of the fatty crystals to selfassemble into stable and metastable structures in their multiple solid phases ${ }^{4-7}$. Also, in a mixture, fatty components can also present mutual miscibility or even total immiscibility in the solid ${ }_{45}$ phase ${ }^{8,9}$. Consequently, apart from the fact that such phenomena largely affect microstructural changes and, therefore, the set of industrial quality requirements of products, numerous operational and economical reasons emphasize the importance of a critical thermodynamic evaluation of the fatty systems for process design 50 and optimization.

This review is aimed at providing an overview on the current understanding of the solid-liquid equilibrium behavior of fatty systems and on the approaches used in the literature for their modeling, taking into account that a deeper knowledge on solid-

55 liquid equilibrium of fatty compounds is still required. The complex nature of fats and oils suggests that the discussion on their phase equilibrium is best tackled starting with the simplest systems. As the complexity of the system increases, the efforts for obtaining a better understanding of the systems behavior also 60 increases. Knowing that fatty systems comprises a large class of compounds, this review addresses mixtures comprising these components directly found in vegetable oils, namely acylglycerols (mono-, di- and triacylglycerols) and fatty acids, as well as those directly produced from these sources, namely fatty 65 alcohols and esters.

\section{What do fats and oils provide?}

Fats and oils are composed of at least $90 \%$ of triacylglycerols plus a set of minoritary components ${ }^{10}$ but a lot of further information can be added to this very simplified view. First of all, 70 triacylglycerols are esters built by a glycerol moiety and three long-chain organic acids. Such fatty acids mostly range from 8 to 20 carbons comprising both saturated and unsaturated compounds. Table 1 shows the mostly frequently found fatty acids in the triacylglycerols present in vegetable oils. Thus, 75 taking also into account that such set of organic chains varies into 3 positions in the glycerol moiety structure, those $90 \%$ of triacylglycerols constitute, in fact, a very large variety of molecules. Therefore, assuming that the carbon-chain length and the number of unsaturations in the molecule have a significant 80 effect on the feedstock's physicochemical properties, the 
knowledge of the composition of the oil is crucial.

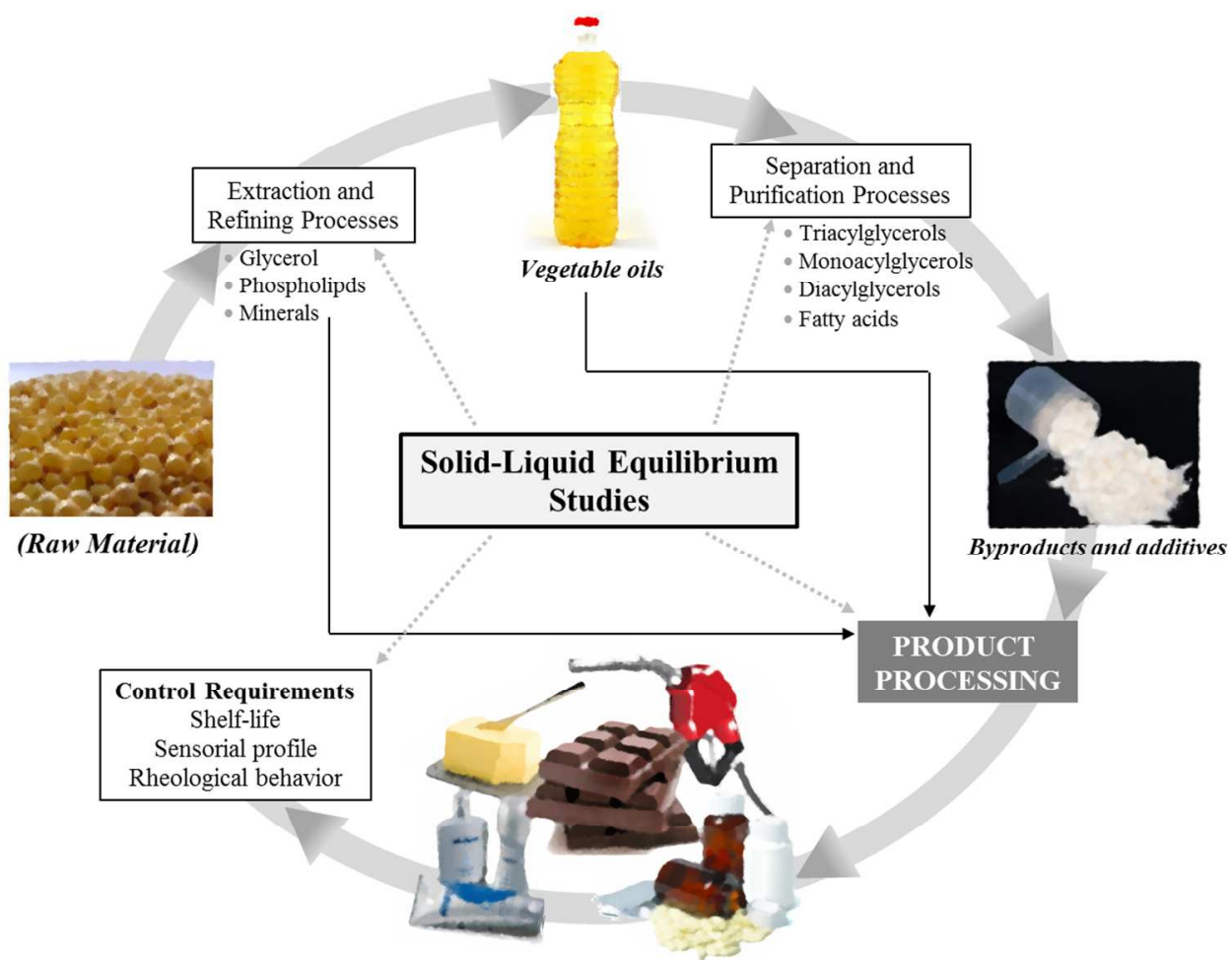

Fig. 1 Action fields of the solid-liquid equilibrium studies on the vegetable oils processing industries.

Table 1 Fatty acid mass composition of vegetable oils

\begin{tabular}{|c|c|c|c|c|c|c|c|c|c|c|}
\hline Source & $\begin{array}{c}< \\
\mathrm{C} 12\end{array}$ & $\begin{array}{l}\text { C12:0 } \\
\text { Lauric }\end{array}$ & $\begin{array}{c}\text { C14:0 } \\
\text { Myristic }\end{array}$ & $\begin{array}{l}\text { C16:0 } \\
\text { Palmitic }\end{array}$ & $\begin{array}{c}\text { C16:1 } \\
\text { Palmitoleic }\end{array}$ & $\begin{array}{l}\text { C18:0 } \\
\text { Stearic }\end{array}$ & $\begin{array}{l}\text { C18:1 } \\
\text { Oleic }\end{array}$ & $\begin{array}{c}\text { C18:2 } \\
\text { Linoleic }\end{array}$ & $\begin{array}{c}\mathrm{C} 18: 3 \\
\text { Linolenic }\end{array}$ & $\begin{array}{c}> \\
\mathrm{C} 18\end{array}$ \\
\hline Rice brain $^{11}$ & - & - & 0.96 & 18.17 & 0.61 & 1.54 & 38.50 & 35.61 & 2.67 & 1.92 \\
\hline Palm oil ${ }^{12}$ & 0.17 & 1.15 & 1.24 & 40.68 & 0.15 & 4.72 & 41.78 & 8.84 & 0.18 & 0.68 \\
\hline Macadamia nut oil ${ }^{13}$ & - & - & 0.98 & 9.38 & 19.28 & 3.40 & 59.76 & 2.03 & 0.14 & 5.02 \\
\hline Brazil nut oil ${ }^{13}$ & - & - & - & 15.86 & - & 11.34 & 30.68 & 42.12 & - & - \\
\hline Cottonseed oil ${ }^{14}$ & - & - & 0.32 & 15.53 & 0.12 & 3.40 & 21.23 & 54.07 & 4.59 & 0.72 \\
\hline Jatropha curcas oil ${ }^{15}$ & - & - & 0.06 & 13.34 & 0.89 & 6.30 & 41.68 & 37.00 & 0.21 & 0.34 \\
\hline Canola oil ${ }^{12}$ & - & - & 0.07 & 4.72 & 0.25 & 2.55 & 62.56 & 20.13 & 7.08 & 9.62 \\
\hline Soybean oil ${ }^{12}$ & - & - & 0.09 & 11.18 & 0.09 & 4.13 & 25.62 & 50.88 & 4.97 & 1.49 \\
\hline Coconut oil ${ }^{16}$ & 13.10 & 51.00 & 23.0 & 6.10 & 6.10 & - & - & - & - & - \\
\hline Crambe oil ${ }^{17}$ & - & - & - & 2.07 & - & 1.03 & 19.38 & 8.33 & 4.53 & 64.66 \\
\hline Fooder radish oil ${ }^{17}$ & - & - & - & 5.11 & - & 2.36 & 39.47 & 16.69 & 12.19 & 24.18 \\
\hline Macauba oil ${ }^{17}$ & - & - & - & 21.80 & 4.08 & 2.76 & 58.97 & 11.64 & 0.75 & - \\
\hline Cuphea oil ${ }^{18}$ & - & 76.40 & 7.80 & 2.40 & - & 0.70 & 5.90 & 6.90 & 0.10 & - \\
\hline Olive oil ${ }^{18}$ & - & - & - & 11.00 & 0.80 & 2.20 & 72.50 & 7.90 & 0.60 & - \\
\hline Grapeseed oil ${ }^{19}$ & - & 0.03 & 0.11 & 8.14 & 0.16 & 4.05 & 15.12 & 71.20 & 0.57 & 0.52 \\
\hline Cocoa butter ${ }^{18}$ & - & 0.10 & 25.40 & 0.20 & 33.20 & 32.6 & 2.80 & 0.10 & - & - \\
\hline Palm kernel oil ${ }^{18}$ & 54.20 & 16.40 & 8.10 & - & 2.80 & 11.4 & 1.60 & - & - & - \\
\hline Buriti fruit oil ${ }^{20}$ & - & 0.03 & 0.08 & 16.78 & 0.32 & 1.77 & 74.06 & 4.94 & 1.04 & 0.83 \\
\hline Tucum oil $^{21}$ & 3.60 & 50.60 & 23.70 & 5.30 & - & 2.50 & 9.30 & 3.60 & 0.10 & 0.10 \\
\hline Sunflower oil 22 & - & 0.04 & 0.10 & 6.80 & 0.08 & 4.16 & 22.75 & 63.83 & 0.82 & 1.42 \\
\hline
\end{tabular}

5 Considering a predominant fraction composed by triacylglycerols, but neglecting the other minority set of compounds is a mistake. Crude oils comprise a group of free fatty acids originated from the hydrolysis of the triacylglycerol molecule and consequently, mono-, diacylglycerols and glycerols 10 molecules are also present. Additionally, a fraction of phospholipids (up to $3 \% \mathrm{wt}$ for soybean oil), sterols (up to 1.00 $\%$ wt for primrose oil), carotenes (up to $0.05 \%$ wt for palm oil), chlorophylls (up to $0.10 \% \mathrm{wt}$ for avocado oil), tocopherols and tocotrienols (up to $0.25 \% \mathrm{wt}$ for wheat germ oil) are commonly
15 found, as well as several other non-lipidic compounds, minerals and metal ions $10,18,20,23-25$. Most of them are usually removed or reduced during the refining processes, whilst a set of them still remain on the refined final product, such as phospholipids (up to $3 \mathrm{mg} / \mathrm{kg}$ ), free fatty acids (up to $0,3 \% \mathrm{wt}$ ) and a small amount of 20 pigments, depending on the source. Consequently, after refining processes, vegetable oils comprise so basically triacylglycerols (higher than $97 \% \mathrm{wt}$ ) and partial acylglycerols (up to $3 \% \mathrm{wt}$ ) ${ }^{10}$, $18,20,26$. From the industrial point of view, the presence of such mono- and diacylglycerols highly affects the physicochemical, 
sensorial and rheological profile of the final product, despite their low concentrations. Moreover, they may produce undesirable effects for the quality requirements, such as changes in the crystallization kinetics, stimulating or retardating the nucleation 5 or growth of the crystals, solidification at low temperatures, changing the strain, stress and the yield force during the flow or emulsification of the system, preventing the effectiveness of separation processes, etc. ${ }^{5,10,27,28}$

Although compounds are usually removed during refining 10 processes, they may be also deliberately added to the fat and oils or other derived products in order to play significant roles in the final profile of the product. In fact, even some triacylglycerols not present in the original crude oil are sometimes added to the product in order to obtain the desired effects. Additionally, they 15 are also used for the production of other additives in the industry, such as fatty alcohols and fatty esters. Fatty alcohols are produced from fatty acids or even from triacylglycerols by different routes of esterification and hydrogenation ${ }^{29}$, but are also found in small amounts in vegetable waxes such as those from 20 sugar cane, sunflower or peanuts ${ }^{30}$. Fatty esters are produced by transesterification of triacylglycerols using alcohols. Both are widely used for the production of several other additives, especially surfactants, for food and cosmetic products ${ }^{31-33}$. Furthermore, several works have long since been evaluating the 25 use of fatty acid esters mixtures as an alternative fuel for the replacement of fossil fuels. The transesterification process for the biodiesel production is mainly based on the utilization of methanol, but also ethanol, in convergence to the larger production of sugar-cane, especially provided by several 30 emerging countries ${ }^{34-36}$.

\section{The solid-liquid equilibrium of fatty systems}

The nature of the solid-liquid equilibrium of fatty mixtures is complex. Comprising multiple solid phases at the same temperature and pressure condition, literature very frequently 35 fails to correctly describing the phase behavior of these mixtures and this becomes worst as more complex behaviors are observed. What makes the SLE of fatty mixtures so particular is their inherent ability to polymorphism phenomena ${ }^{4,7,37,38}$. It means that the long-hydrocarbon chains of the fatty compounds and 40 consequently their crystal lattice can be configured into numerous micro- and macromolecular arrangements, directly related to the thermal treatment to which the mixture is submitted. Triacylglycerols, particularly, present three classical and well known polymorphic forms: $\alpha, \beta$, and $\beta$, not accounting for 45 additional sub modifications that also appear during thermal processes. The first structure is formed into fast cooling. When submitted to a slow heating, such arrangement melts and is recrystallized into a more stable structure, the $\beta$ ' form, and sequentially into the $\beta$ form. Since different crystal lattices are so observed in these cases, namely hexagonal, orthorhombic and triclinic, different transition temperatures and enthalpies are also observed. Crystalline structure of fatty acids, alcohols and esters can also pack into different polymorphic forms, usually in temperatures very close to the most stable form 9, 37, 39, 40 . ${ }_{55}$ Knowing that the polymorphism phenomena can be managed by particular thermal treatments, the parameters of the processes to which mixtures are submitted, time and temperature, can define the profile of the final product.

Evolution. The first studies on SLE of fatty mixtures ${ }_{60}$ published in the literature presented only the melting temperature behavior, also known as the liquidus line (1--44 $^{4}$ and most of them only in a restricted concentration range, such that phase diagrams could not be completely represented. On the other hand, the interest on the solid-liquid transitions of these systems as well as ${ }_{65}$ the capacity of a better characterization of their solid phases has grown significantly in the last decades. Table 2 shows the set of binary fatty mixtures that have already been reported in the open literature. Efforts to better characterize these systems have been growing, but increasing also the complexity of their description. 70 In this context, four principal types of phase diagrams could be identified for binary mixtures, as sketched in Figure 2.

The first and simplest phase diagram is the so-called eutectic (Figure 2 A). Some binary mixtures of fatty acids, mixtures of fatty esters or systems composed by fatty acids and fatty alcohols 75 present this behavior. Simple-eutectic mixtures are such that during the cooling process, their compounds crystallize independently. The eutectic point establishes the concentration at which the system melts at a single, well defined, and minimum temperature. In a simple eutectic system there are 4 domains: one 80 homogeneous liquid phase (l); two biphasic solid-liquid domains (regions $C^{a}+l$ and $C^{b}+l$ ); and one biphasic solid-solid domain (region $C^{a}+C^{b}$ ). In such a system when a solid mixture is heated it starts to melt always at the same temperature (eutectic temperature) and the composition of the liquid phase changes 85 along one of the branches of the liquidus line according to the initial concentration of the solid mixture.

The second case (Figure $2 \mathrm{~B}$ ) shows the phase diagram of a mixture with solid solution in the extremes of the phase diagram. Depending on concentration of the mixture, the molecules of a 90 compound are incorporated into the lattice of another crystal ${ }^{45}$ during crystallization. It means that within this concentration range, in general close to one of the pure components, the compounds do not crystallize independently. In case of lipidic systems, solid solutions are particularly interesting because they ${ }_{95}$ can be intentionally developed such that physicochemical properties could be adjusted to specific requirements ${ }^{46-48}$. Several fatty binary mixtures present solid solution formation at some concentrations, especially those composed of triacylglycerols or fatty alcohols $4,8,49,50$. The phase diagrams of such mixtures 100 comprise 6 domains as shown in Figure 2 B. The domains are explicitly circumscribed by two boundaries: the liquidus line, in which the last crystal of the mixture melts, and the solidus line indicates the limits of the melt of the first crystal. The eutectic point in this case establishes a triphasic equilibrium in which the 105 liquid phase is in equilibrium with two solid solutions with distinct compositions. The evaluation of the eutectic point and the solubility region of the solid phase is usually carried out using the Tammann plot (Figure 3) ${ }^{50-53}$. This diagram relates the enthalpy of the eutectic reaction as a function of the mixture concentration 110 in which the enthalpy rises up to the eutectic point when it begins to decrease. The concentration at which the solid solution is formed is obtained when enthalpy of such reaction $\Delta H_{\text {eut }}=0$. 

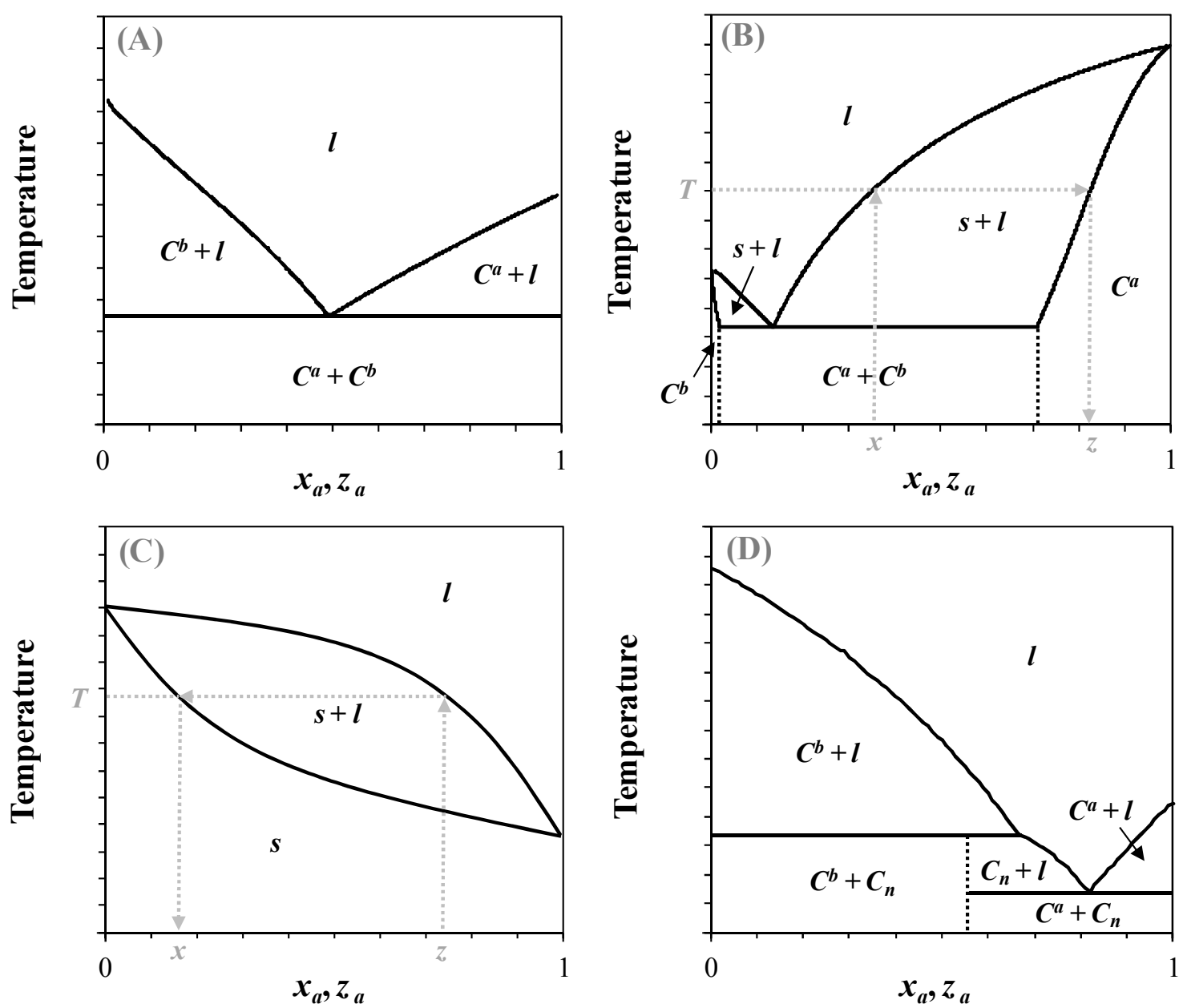

Fig. 2 Most common phase diagrams of binary fatty mixtures with the following nomenclature: mole fraction of the component $a$ in the liquid $\left(x_{\mathrm{a}}\right)$ and solid $\left(z_{\mathrm{a}}\right)$ phases, respectively, liquid phase $(l)$, solid phase with pure or rich in component $a\left(C^{a}\right)$ or $b\left(C^{b}\right)$, solid phase comprising both compounds $(s)$, solid phase with new structure formed by peritectic transition $\left(C_{\mathrm{n}}\right)$.

5

A behavior not so common occurs when the components of the liquid phase crystallize as a solid solution throughout the entire concentration range. It means that only 3 domains are observed (Figure $2 \mathrm{C}$ ): the liquid region, the solid domain and the region of 10 coexistence of both liquid and solid phases. Many mixtures of triacylglycerols with similar molecular sizes, such as PPS (Glycerol 1,2-palmitate,3-stearate) + PPP (tripalmitin) or SOS (Glycerol 1,3-stearate,2-oleate) + POS (Glycerol 1-palmitate,2oleate,3-stearate) ${ }^{4}$ are able to form solid solutions. In this case, 15 systems are continuous solid solutions.

Frequently, in the crystallization processes of lipidic compounds, associative phenomena can occur during the building of the crystal lattice. Such associative behavior may lead to the appearance of a new crystalline structure that acts as a new 20 compound. This is the so-called peritectic reaction. This reaction is defined as an isothermal and reversible process between a liquid and a solid phase resulting, during the cooling of a system, in new solid phases ${ }^{45}$. It is possible to understand such phenomena taking into account the inherent polymorphic ability 25 of fatty compounds. Some works suggest to interpret such phenomenon as a chemical reaction so that the original components form a product according to a specified stoichiometry. If the new compound crystallizes independently of the mixture's compounds the phase diagram behavior is that ${ }_{30}$ presented in Figure 2 D. This means that there are two biphasic solid regions, each with two immiscible crystalline structures, the new compound $C_{\mathrm{n}}$ and one of the pure components of the original mixture $C^{b}$ or $C^{a}$, Furthermore, there are 3 solid-liquid domains involving one of the pure components in the crystalline form and 35 the liquid phase or the new compound and the liquid phase. Note that the new compound exists only in the solid phase, and disappears during the system's melting. Works in literature report 
the appearance of peritectic profiles in binary mixtures of fatty acids and some systems composed by methyl esters $9,39,40,54$.

Despite the classification of many fatty mixtures into the typical four phase diagrams shown in Figure 2, the understanding 5 of the phase behavior of the fatty systems is still far from complete. It is not uncommon that the solid phase presents further transitions that remain to be clarified ${ }^{55}$. Metatectic transitions have also been identified on these systems. In this case, the mixture can recrystallize during the melting process, i.e on
10 heating above the solidus line ${ }^{40}$. It means that the crystalline profile of the solid phase clearly changes and probably a corresponding set of other particular properties. Recent studies 9, 40, 54 describe fatty systems with up to 15 different domains (Figure 4). In these mixtures all the phenomena previously 15 discussed are present in a single phase diagram, depending on concentration and temperature: eutectic, peritectic and metatectic transitions as well as partial miscibility of the solid phases.

Table 2 Solid-liquid phase diagrams of binary mixtures of fatty compounds reported in literature.

\begin{tabular}{|c|c|c|c|c|c|}
\hline System & $\begin{array}{c}\text { Phase } \\
\text { Diagram }\end{array}$ & Ref. & System & $\begin{array}{c}\text { Phase } \\
\text { Diagram }\end{array}$ & Ref. \\
\hline & & & Fatty ester + fatty ester & & \\
\hline Fatty acids + fatty acids & & & Ethyl caprylate + ethyl palmitate & E & 56 \\
\hline Caprilic acid + capric acid & $\mathrm{ESS} / \mathrm{P} / \mathrm{M}$ & 40 & Ethyl caprylate + ethyl stearate & $\mathrm{E}$ & 57 \\
\hline Caprilic acid + lauric acid & $\mathrm{ESS} / \mathrm{P} / \mathrm{M}$ & 9 & Ethyl caprate + ethyl palmitate & $\mathrm{E}$ & 56 \\
\hline Caprilic acid + myristic acid & $\mathrm{ESS} / \mathrm{P} / \mathrm{M}$ & 54 & Ethyl caprate + ethyl stearate & $\mathrm{E}$ & 57 \\
\hline Caprilic acid + oleic acid & ESS & 52 & Ethyl laurate + ethyl palmitate & $\mathrm{E}$ & 56 \\
\hline Capric acid + lauric acid & $\mathrm{ESS} / \mathrm{P} / \mathrm{M}$ & 40,58 & Ethyl laurate + ethyl stearate & $\mathrm{E}$ & 57 \\
\hline Capric acid + myristic acid & $\mathrm{ESS} / \mathrm{P} / \mathrm{M}$ & 9,58 & Ethyl myristate + ethyl palmitate & $\mathrm{E}$ & 56 \\
\hline Capric acid + palmitic acid & $\mathrm{ESS} / \mathrm{P} / \mathrm{M}$ & 54,58 & Ethyl myristate + ethyl stearate & $\mathrm{E}$ & 57 \\
\hline Capric acid + stearic acid & $\mathrm{E}$ & 58 & Ethyl palmitate + ethyl stearate & $\mathrm{E}$ & $57,59,60$ \\
\hline Capric acid + oleic acid & ESS & 52,61 & Ethyl palmitate + ethyl oleate & $\mathrm{E}$ & 56 \\
\hline Lauric acid + myristic acid & $\mathrm{ESS} / \mathrm{P} / \mathrm{M}$ & 40,58 & Ethyl palmitate + ethyl linoleate & $\mathrm{E}$ & 56 \\
\hline Lauric acid + palmitic acid & $\mathrm{ESS} / \mathrm{P} / \mathrm{M}$ & 9,58 & Ethyl stearate + ethyl oleate & $\begin{array}{l}\mathrm{L} \\
\mathrm{E}\end{array}$ & 57 \\
\hline Lauric acid + stearic acid & $\mathrm{ESS} / \mathrm{P} / \mathrm{M}$ & 54,58 & Ethyl stearate + ethyl linoleate & $\mathrm{E}$ & 57 \\
\hline Lauric acid + oleic acid & $\mathrm{E}$ & 62 & Methyl laurate + methyl palmitate & $\mathrm{E}$ & 63 \\
\hline Myristic acid + palmitic acid & $\mathrm{ESS} / \mathrm{P} / \mathrm{M}$ & 40 & Methyl myristate + methyl palmitate & $\mathrm{ESS} / \mathrm{P} / \mathrm{M}$ & $39,63,64$ \\
\hline Myristic acid + stearic acid & $\mathrm{ESS} / \mathrm{P} / \mathrm{M}$ & 9 & Methyl myristate + methyl stearate & $\mathrm{ESS} / \mathrm{P} / \mathrm{M}$ & 39 \\
\hline Myristic acid + oleic acid & $\mathrm{E}$ & 62 & Methyl palmitate + methyl stearate & $\mathrm{ESS} / \mathrm{P} / \mathrm{M}$ & $39,59,63$ \\
\hline Palmitic acid + stearic acid & $\mathrm{ESS} / \mathrm{P} / \mathrm{M}$ & 40 & Methyl palmitate + methyl oleate & $\mathrm{E}$ & 63 \\
\hline Palmitic acid + oleic acid & $\mathrm{E}$ & 65 & Mehtyl palmitate + methyl linoleate & $\mathrm{E}$ & 63 \\
\hline Palmitic acid + linoleic acid & $\mathrm{E}$ & 65 & Methyl stearate + methyl oleate & $\mathrm{E}$ & 63 \\
\hline Oleic acid + stearic acid & $\mathrm{E}$ & 61,66 & Methyl stearate + methyl linoleate & $\mathrm{E}$ & 63 \\
\hline \multirow[t]{2}{*}{ Oleic acid + linoleic acid } & $\mathrm{E}$ & 61 & Methyl oleate + methyl linoleate & $\mathrm{E}$ & 63 \\
\hline & & & Triacylglycerol + triacylglycerol & & \\
\hline Fatty alcohols + fatty alcohols & & & Tricaprylin + tristearin & ESS & 4 \\
\hline 1-octanol + 1-decanol* & $\mathrm{ESS} / \mathrm{P} / \mathrm{M}$ & 67 & Trilaurin + tripalmitin & ESS & 4 \\
\hline 1-decanol + 1-dodecanol & $\mathrm{ESS} / \mathrm{P} / \mathrm{M}$ & 67 & Trilaurin + tristearin & ESS & 4 \\
\hline 1-dodecanol + 1-tetradecanol & $\mathrm{Y}$ & 68 & Trimyristin + tripalmitin & ESS & 4 \\
\hline 1-dodecanol +1 -hexadecanol & $\mathrm{ESS} / \mathrm{P} / \mathrm{M}$ & 67 & Tripalmitin + tristearin & ESS & 50 \\
\hline 1-dodecanol + 1-octadecanol & ESS & 49 & Tripalmitin + triolein & ESS & $4,50,65$ \\
\hline 1-tetradecanol +1 -hexadecanol & Y & 68 & Tripalmitin + trilinolein & ESS & 65 \\
\hline 1-tetradecanol + 1-octadecanol & $\mathrm{ESS} / \mathrm{P} / \mathrm{M}$ & 67 & Tristearin + triolein & $\mathrm{E}$ & 4 \\
\hline \multirow[t]{3}{*}{ 1-hexadecanol + 1-octadecanol } & SS & 60,69 & & & \\
\hline & & & Triacylglycerol + fatty acid & & \\
\hline & & & Tricaprylin + myristic acid & $\mathrm{E}$ & 70 \\
\hline Fatty acid + fatty alcohol & & & Tripalmitin + oleic acid & ESS & 61,65 \\
\hline Capric acid + 1-dodecanol & $\mathrm{ESS} / \mathrm{P}$ & 71 & Tripalmitic + linoleic acid & ESS & 65 \\
\hline Lauric acid + 1-dodecanol & $\mathrm{P}$ & 71 & Tristearin + palmitic acid & ESS & 50 \\
\hline Lauric acid + 1-tetradecanol & ESS & 8 & Tristearin + linoleic acid & ESS & 50 \\
\hline Myristic acid + 1-dodecanol & $\mathrm{P}$ & 71 & Triolein + palmitic acid & E & 65,70 \\
\hline Myristic acid + 1-tetradecanol & $\mathrm{P}$ & 71 & Trilinolein + palmitic acid & $\mathrm{E}$ & 65 \\
\hline Myristic acid + 1-hexadecanol & $\mathrm{E}$ & 8 & Trilinolenin + stearic acid & $\mathrm{E}$ & 70 \\
\hline Palmitic acid + 1-dodecanol & $\mathrm{P}$ & 71 & & & \\
\hline Palmitic acid + 1-tetradecanol & $\mathrm{E}$ & 71,72 & Triacylglycerol + fatty alcohol & & \\
\hline Palmitic acid + 1-hexadecanol & $\mathrm{P}$ & 71 & Trilaurin + 1-hexadecanol & ESS & 73 \\
\hline Palmitic acid + 1-octadecanol & ESS & 8 & Trilaurin + 1-octadecanol & $\mathrm{E}$ & 73 \\
\hline Stearic acid + 1-dodecanol & $\mathrm{E}$ & 71 & Trimyristin +1 -hexadecanol & ESS & 73 \\
\hline Stearic acid + 1-tetradecanol & $\mathrm{E}$ & 71 & Trimyristin + 1-octadecanol & ESS & 73 \\
\hline Stearic acid + 1-hexadecanol & $\mathrm{P}$ & 71 & Tripalmitin + 1-hexadecanol & ESS & 73 \\
\hline \multirow{3}{*}{ Stearic acid +1 -octadecanol } & $\mathrm{P}$ & 71,74 & Tripalmitin + 1-octadecanol & ESS & 73 \\
\hline & & & Triolein + 1-hexadecanol & E & 51 \\
\hline & & & Triolein + 1-octadecanol & $\mathrm{E}$ & 51 \\
\hline
\end{tabular}

$\mathrm{E}=$ Simple eutectic, $\mathrm{P}=$ Peritect, $\mathrm{M}=$ Metatectic, $\mathrm{ESS}=$ Eutectic with partial miscibility in the solid phase, $\mathrm{SS}=$ Continuous solid solution, $\mathrm{Y}=$ not 20 defined. 


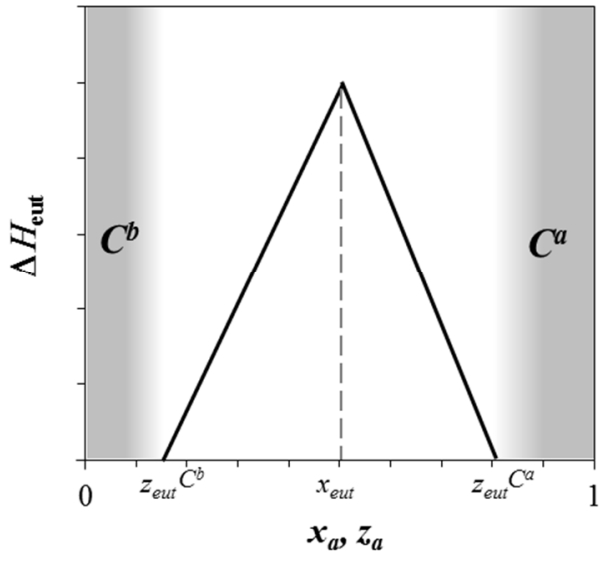

Fig. 3 Tammann plot of the eutectic reaction: enthalpy of the eutectic reaction as a function of the concentration of the mixture (full line); mole fraction of the component $a$ at the eutectic point in the liquid phase $x_{\text {eut }}$ 5 (dashed line), and in the solid phases $\left(z_{\text {eut }}\right)$ rich in the component $a\left(C^{a}\right)$ or $b\left(C^{b}\right)$; represented in gray, solid solution regions rich in the component $a$ or $b$.

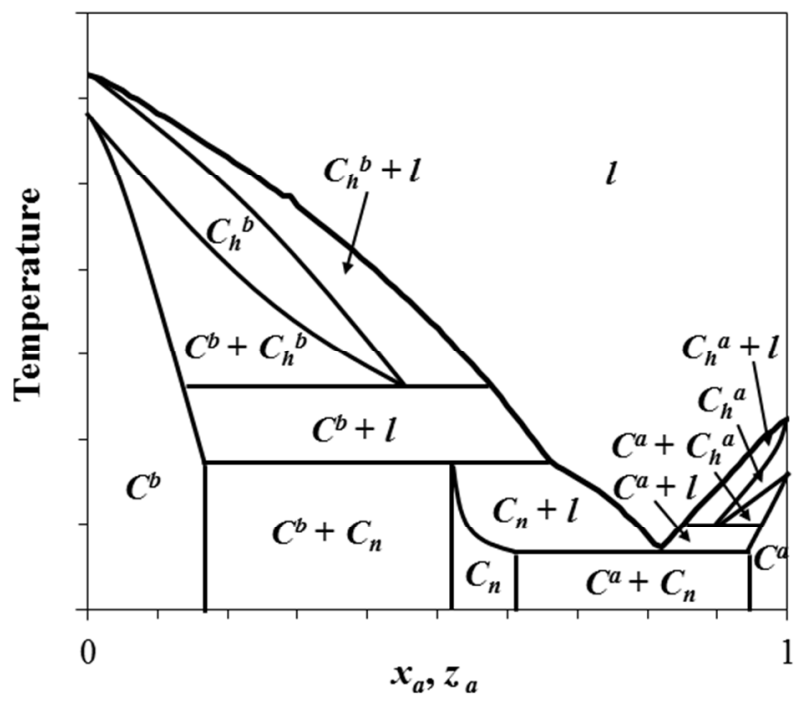

10 Fig. 4 Sketch of the SLE phase diagram observed in mixtures of fatty acids (as presented by Costa, et al. ${ }^{9}$ ) for some fatty acid + fatty acid binary systems. $C^{a}$ and $C^{b}$ are the solid solutions rich in one of the components of the mixture $a$ or $b ; C_{n}$ is the solid phase formed by the peritectic reaction; $C_{h} a$ and $C_{h} b$ are the solid phases formed after the metatectic reaction; $l$ is the liquid phase.

In fact, a large set of fatty binary mixtures were not evaluated yet: mixtures of triacylglycerols; systems composed of triacylglycerols and fatty acids, alcohols or esters; systems 20 comprising methylic and ethylic fatty esters; mixtures of fatty esters and fatty acids or alcohols; not to mention a long list of mono- and diacilglycerols mixtures. Also, studies comprising the effect of cis-trans isomerism in the melting point of lipidic mixtures are yet scarce. It is known that the melting point of 25 trans-isomers are higher than cis-ones ${ }^{75}$. This is noteworthy taking into account that trans-fatty compounds can be formed during industrial processes and are related to coronary heart diseases ${ }^{76}$. Moreover, beyond these binary fatty systems, many works in literature, aiming at the design of products and ${ }_{30}$ processes, have been evaluating the SLE of binary systems of these fatty compounds with other organic solvents such as cyclohexane and ethanol ${ }^{77}$, alkanes ${ }^{78}$, aromatic compounds ${ }^{79}$ and drugs ${ }^{80}$. Additionally, the SLE of many lipid-derivative based mixtures composed of surfactants ${ }^{81}$, phospholipids ${ }^{53}$, 35 glycolipids ${ }^{82}$, lipidic-based ionic liquids ${ }^{83}$ or aqueous mixtures of partial acylglycerols ${ }^{84}$ have also been reported, aiming at formulation of food or personal care products, supporting media ${ }^{85}$, or drug delivery systems ${ }^{86}$. These mixtures display a set of liquid crystalline states or mesophases. Such mesophases are 40 called as the "forth state of matter" since their physicochemical properties are similar than those of a liquid state but the oriented nature of the molecules confers particular properties of a solid state ${ }^{87}$. The presence of these mesophases highly increases the complexity of the system equilibrium.

45 In summary, all these works reveals the diversity of the solidliquid equilibrium behavior of lipidic mixtures but also that several experimental studies are still required for a detailed characterization and understanding of these systems.

\section{Brief overview on the techniques for measuring ${ }_{50}$ SLE data}

The temperatures and enthalpies of the transitions of both solidliquid and solid-solid phenomena, including those due to the polymorphic transitions, can be obtained by differential scanning calorimetry (DSC). Such a technique is classically used for the 55 description of solid-liquid phase diagrams of fatty systems. However, owing to the polymorphism of the solid phase, multiple crystalline structures can be present in a mixture. Thus, some authors in literature ${ }^{58}$ propose that samples should be submitted to a thermal treatment before the measurement of the melting ${ }_{60}$ properties. First, with complete melting of the mixture, the previously organized crystalline structures, that literature calls thermal history, are deleted. Knowing that the polymorphic forms are highly dependent on the temperature and the heating/cooling rates, specific procedures are required in order to assess the 65 temperatures and enthalpies of such different crystal structures. This can be reached by melting the sample above the highest melting point of the components, cooling at low rates, followed by an isothermal treatment at a very low temperature and a slow heating run up to the melting of the component or mixture of 70 compounds. In fact, the DSC method is not a classical static method for the determination of equilibrium data. However, slow rates allow to assess a quasi-equilibrium state in which crystal structures can be rearranged such that temperatures and 
enthalpies of the transitions are measured. Moreover, this technique is also able to detect endo- and exothermic events; it means that it detects not only melting transitions but recrystallization phenomena of the solid phase, such as 5 polymorphic or metatectic transitions.

Besides DSC, a set of other analytical tecniques, such as X-ray diffraction, microscopy and nuclear magnetic resonance (NMR), are frequently required in order to characterize in more detail the phase behavior of the system and are often used in the literature 10 for the evaluation of fatty mixtures ${ }^{5,9,28,47,88}$. Single-crystal and powder X-ray diffraction tecniques allow assess information on the crystal structure of the pure compounds and their mixtures. On the molecular point of view, through the knowledge of the molecular structure of the compounds, enthalpic and entropic 15 molecular interactions can be inferred and the ideal/non-ideal thermodynamic behavior of the mixture explained. Controlledtemperature microscopy allows the visual observation of the beggining and the end of the melting, crystallization and recrystallization phenomena, and the evalution of the growth and ${ }_{20}$ disapearance of the crystals. NMR is the most applied experimental technique to describe the solid fat content (SFC) curve of fatty mixtures in the fats and oils industry. The manipulation of the mixtures' solid fraction is of utmost importance since it provides parameters to monitor industrial 25 processes and product formulation. Information obtained by these techniques can clarify the transitions observed by DSC, such as polymorphic transitions, formation of solid solutions, solid phase immiscibility, peritectic and metatectic reactions.

\section{But, in fact, what is literature looking for?}

30 Although several transitions or even complete behaviors have been clarified in the literature, the solid-liquid phase diagrams of various fatty mixtures are still unknown or were published with limited information concerning various aspects of their real behavior. The systematic evaluation of the SLE behavior of fatty 35 systems could enable new applications or help the understanding of unclear industrial or biochemical phenomena involving such substances. In fact, the phase equilibrium study really creates an additive design concept. It means that if one aims to change the nutritional, sensorial or physicochemical profile of a fatty product 40 by the introduction or removal of components, increasing or decreasing the melting point, the evaluation of the phase change profile is essential. In this context, a SLE phase diagram is a powerful tool.

The solid-liquid equilibrium of fatty systems had been long 45 evaluated to obtain an assessment on the description of numerous processes or development of products ${ }^{5-7,27,48}$. Some examples can be easily mentioned. a) Optimization of fractionation processes in which the material are separated into fractions depending on the melting point by a set of crystallization 50 procedures ${ }^{89}$; b) Optimization of interesterification processes in which fatty acids moieties are added or removed from the triacylglycerols in order to obtain lower or higher melting points materials. This process is a classical alternative for the replacement of the hydrogenation procedure which promotes the 55 formation of saturated or trans-unsaturated fatty compounds related as precursors of cardiovascular diseases ${ }^{10} ; \mathrm{c}$ ) Development of structured lipids for the improvement of the nutritional or physicochemical characteristics of the product. This process involves chemical or enzymatic pathways and is aimed at ${ }_{60}$ the modification of the triacylglycerols' fatty acid profile ${ }^{38}$; d) Control of crystallization phenomena in lubricants or oils for frying processes, in which solid particles or even compounds that could promote crystallization are undesirable or in butters, creams and analogous products, in which the crystalline structure ${ }_{65}$ is responsible for the desired texture $5,6,27,48$

Other special cases take into account the production of new materials for the applications in food, pharmaceutical, materials or energy industries. Mixtures of fatty acids and fatty alcohols, for example, had been evaluated for the formulation of 70 organogels 90,91 and phase change materials ${ }^{92-94}$. Moreover, mixtures of fatty esters have long been used as biofuels where the crystallization of saturated esters is a major challenge limiting their operation at low temperatures $35,36,39,95,96$.

Organogels are structured materials formed by self-assembling of 75 the components through noncovalent interactions. They can become an alternative for structuring fat-based systems making possible to replace traditional industrial processes as hydrogenation, fractionation and interesterification. Fatty acids and alcohols are compounds ${ }^{31,32}$ that can replace saturated fats 80 by acting as gelator agents and promoting the formation of organogels. Thus, the rheological properties of these products can be controlled by formation of structured networks with different packing arrangements and particular shear strain and stress profiles ${ }^{97}$.

${ }_{85}$ Phase change materials are materials for energy storage. Concerning a phase-change heat storage system, energy could be stored and released by reversible solid-solid or solid-liquid phase changes. Fatty acids, alcohols and esters have relative low melting point, low vapor pressure, low toxicity and high latent 90 heats, being suitable for thermal storage processes. ${ }^{92,98}$ Such materials play an important role as an environmentally friend way of accumulating and saving energy, replacing traditional storage fluids such as those used in refrigeration systems and contributing for the reduction of the emission of greenhouse-gases.

95 Biodiesel is a mixture of the mono-alkyl esters obtained as derivatives of fat and oils and thus, it is a renewable energy source. Consequently, they are environmentally attractive, promoting the reduction of the emission of pollutant gases in replacement of fossil fuels. Because of this, nowadays, biodiesel 100 is mandatorily added to petrodiesel in several countries. However, the biofuel industry is still looking for alternatives to overtake several technical problems associated to biodiesel production, storage and use. The solidification at low temperatures is one of them. The presence of fatty esters with 105 high melting temperature, such as methyl stearate and methyl palmitate is a factor that makes difficult the use of this biofuel at low temperatures. Moreover, other minor components such as monoacylglycerols of saturated fatty acids can also be present and can precipitate in the storage tanks at low temperatures 110 leading to the clogging of tubes and filters of the vehicles. In all these cases a deeper knowledge of the solid-liquid equilibrium of fatty mixtures can help optimizing industrial processes and improving the formulation of products with desirable properties.

\section{Demands on modeling}


This growing number of new experimental data has not been followed by proportional efforts to better model these complex phase diagrams. The greater the interest in new systems or applications, the higher the demand to improve reliable modeling 5 approaches. The modeling of the melting profile of lipidic systems is best tackled by depicting the melting temperature $T$ as a function of the composition of the mixture or, in other words, by depicting the phase diagram. This problem is solved by evaluating the well known thermodynamic equilibrium condition. ${ }_{10}$ The thermodynamic equilibrium is established when at the same temperature and pressure, the chemical potential of a compound in every phase is also the same, in the present case, a liquid and a solid phase. Theoretically, Equation 1 relates the mole fraction of the component $i$ in the liquid phase $x_{\mathrm{i}}$ and the melting temperature ${ }_{15} T_{\text {fus }}$ and enthalpy $\Delta_{\text {fus }} H$ of the pure compound, so that the melting temperature of the mixture $T$ can be calculated ${ }^{99}$.

$$
\ln x_{\mathrm{i}}=\frac{\Delta_{\text {fus }} H}{R}\left(\frac{1}{T_{\text {fus }}}-\frac{1}{T}\right)
$$

where $R$ is the gas constant. However, this equation is far from being adequate to accurately depict the real state of the system. 20 The SLE can be fully considered, and so better described, by Equation $2^{99,100 .}$

$$
\begin{aligned}
\ln \frac{x_{\mathrm{i}} \gamma_{\mathrm{i}}^{\mathrm{L}}}{z_{\mathrm{i}} \gamma_{\mathrm{i}}^{S}}=\frac{\Delta_{\text {fus }} H}{R}\left(\frac{1}{T_{\text {fus }}}-\frac{1}{T}\right)+ & \sum_{\text {tr }}^{n}\left[\frac{[}{R}\left(\frac{\Delta_{\mathrm{tr}} H}{T_{\text {tr }}}-\frac{1}{T}\right)\right] \\
& +\frac{\Delta_{\text {fus }} C_{p}}{R}\left(\frac{T_{\text {fus }}}{T}-\ln \frac{T_{\text {fus }}}{T}-1\right)
\end{aligned}
$$

where $z_{\mathrm{i}}$ is the mole fraction of component $i$ in the solid phase, $\gamma_{\mathrm{i}}^{\mathrm{L}}$ and $\gamma_{\mathrm{i}}^{\mathrm{S}}$ are the activity coefficients of component $i$ in the liquid 25 and solid phases, respectively, $T_{\mathrm{tr}}$ and $\Delta_{\mathrm{tr}} H$ are thermal transitions temperatures and enthalpies of the $n$ solid-solid transitions (polymorphic forms) of the component $i$ and $\Delta_{\text {fus }} C_{p}$ is the difference between the heat capacity of the pure component $i$ of the liquid and solid phases. If both equations are compared, it is 30 observed that Equation 1 was built under three main considerations. Firstly, it does not consider the non-ideality of the phases by means of the calculation of the activity coefficients of component $i$ in both phases liquid $\gamma_{\mathrm{i}}^{\mathrm{L}}$ and, if it is the case, solid $\gamma_{i}^{\mathrm{S}}$. Moreover, it assumes that the solid phase is composed of 35 immiscible pure components such that $z_{\mathrm{i}} \gamma_{\mathrm{i}}^{\mathrm{S}}=1.0$. Also, it neglects the presence of polymorphic transitions and so the effects of the thermal transitions temperatures $T_{\text {tr }}$ and enthalpies $\Delta_{\mathrm{tr}} H$ that are present in the heating profile of the components of the mixture.

40 Through Equation 2, the non-ideality of both phases is fully considered. Also, it presents additionally two terms: The first term takes into account the effects of the polymorphic forms of the mixture components on the melting profile. The second one is related to the specific heat capacity $\Delta_{\text {fus }} C_{p}$ that is usually

45 neglected due to a clear lack of reliable experimental data and because the magnitude of this property supposedly does not affect the solid-liquid equilibrium calculation. Moreover, Equation 2 reveals that, the modeling of fatty mixtures' phase diagrams is based on a fundamental problem: the miscibility of the solid 50 phase or the presence of solid solutions, so that $z_{\mathrm{i}} \gamma_{\mathrm{i}}^{\mathrm{S}} \neq 1.0$. This is related to the calculation of the solidus line. The solidus line depicts the behavior of the melting temperature $T$ as a function of the solid phase composition $z_{\mathrm{i}}$.

Despite the fact that solid solutions are more common than 55 usually admitted, most authors have adopted the modeling approach based on the solid phase immiscibility. In the works that take into account a more comprehensive approach and consider the formation of such solid solutions ${ }^{4,38,96}$ two main focuses can be identified. From the academic focus, the solid${ }_{60}$ liquid equilibrium theory is formulated for complete description of the solid-liquid phase diagram of a system of interest, this means for calculating the liquidus and the solidus lines. From the industrial focus, the knowledge of the solid content behavior of a vegetable oil or a mixture of triacylglycerols has a particular ${ }_{65}$ interest for the formulation of products. This behavior is best assessed by the construction of a diagram that represents the solidified fraction of the system as a function of temperature. The aim is the manipulation of the melting point of the mixture by the right choice of its composition. It is known that, for instance, 70 many sensorial aspects, such as crispness, spreadability, aroma and oiliness are largely affected by the solid/liquid ratio in lipidic products, such as cocoa and peanut butters, but also in case of cosmetic creams ${ }^{5,6}$. Analogously, the melting behavior of a biodiesel mixture is largely dependent on the original fat or oil 75 composition as well as the alcohol used in the transesterification reaction ${ }^{35}$. It means that blends with high concentration of long carbon saturated fatty esters are more susceptible to high solid content at low temperatures, worsening their flow properties ${ }^{36,63}$. Other example for the construction of solid fat content diagrams 80 is the development of the so-called structured lipids. By changing the fatty acid composition of triacylglycerols it is possible to improve specific properties ${ }^{38}$. High amounts of saturated or trans-unsaturated fatty acids can, for instance, bring negative effects concerning the nutritional claim of the product and, 85 additionally, can increase its melting point. Thus, by the adequate right choice of fatty acids the desired solid content profile of a mixture can then be designed avoiding, for instance, the presence of trans-unsaturated fatty acids.

In order to assess the SLE described by Equation 2, works in 90 literature apply mainly two well known algorithms: the minimization of the Gibbs energy and the isoenthalpic flash calculation ${ }^{4}$. The first is based on the stability criteria in which a mixture at equilibrium condition present the minimum Gibbs energy. The second one, in analogy with the vapor-liquid 95 equilibrium, considers the feeding of a mixture in an isothermic and isobaric vessel and the equilibrium condition is then calculated through the analysis of the mass balance and the fundamental SLE equations. Both approaches are robust in obtaining the equilibrium state of the mixture but sensitive to 100 initial concentrations estimates.

For the description of the non-ideality of the system, these optimization procedures calculate the activity coefficients of the liquid and solid phases. The activity coefficients of the components in the liquid phase $\gamma_{i}^{\mathrm{L}}$ are usually calculated using 105 equations for the excess Gibbs energy ${ }^{99}$ such as Margules or UNIQUAC equations ${ }^{101}$ or the group-contribution UNIFAC model 102, 103 . Equation 3 shows the 2-suffix Margules equation, commonly used in the SLE modeling of binary systems, 
comprising one adjustable parameter $A_{12}$, related to the interaction between the compounds of the binary.

$$
R T \ln \left(\gamma_{1}{ }^{\mathrm{L}}\right)=A_{12} x_{2}{ }^{2}
$$

where $x$ is the composition of the component in the liquid phase, ${ }_{5} T$ is the melting temperature of the mixture and $R$ is the ideal gas constant. Despite the slight non-linearity of this model, what is favorable in case of optimization procedures, its disadvantage is the calculation of symmetric non-ideal behaviors. It means that the compounds should present positive or negative deviations but 10 not both behaviors depending on the concentration. The UNIFAC equation is a predictive method commonly used in case of liquidliquid and vapor-liquid equilibrium and that can be also applied for the calculation of the $\gamma_{i}^{\mathrm{L}}$ in case of SLE studies ${ }^{103}$. This model is based on the group-contribution concept so that the 15 activity coefficient of the component is calculated by a sum of terms related to enthalpic and entropic interactions. It is well applied for the description of the liquid phase in the SLE of fatty systems presenting slight deviations from ideality. However, the model can fail in the prediction of strong non-ideal behaviors 20 such those observed in cases where the compounds are very different in size.

Two approaches were up to now used for the calculation of activity coefficients of the components in the solid phase of fatty systems: the two-suffix Margules equations ${ }^{4}$ for the description 25 of the solid phase of mixtures of triacylglycerols and a predictive version of the UNIQUAC model ${ }^{96,104}$ for the description of mixtures of fatty esters. Applying Margules equation, Equation 3 is used but evaluating the composition of the compound in the solid phase $z_{\mathrm{i}}$. In the predictive version of the UNIQUAC model, 30 the binary interactions parameters are calculated by using the physicochemical properties of the pure compound, as described by the authors.

Apart from discussions on the effectiveness these approaches, taking into account the description of the lipidic systems listed in 35 Table 2 that present different kind of behaviors as well as numerous mixtures that were not evaluated yet, the SLE modeling of fatty systems is a field yet to be explored.

\section{Remarks}

In this large and opened context, several demands are clearly ${ }_{40}$ evident. The first and most obvious is the enlargement of the number of reliable experimental data of binary, ternaries and even more complex mixtures of fatty systems. Additionally, pure compound experimental data, melting temperatures and enthalpies as well as solid-solid transitions properties and specific 45 heat capacity of the phases are highly demanded, since all of these parameters are required in the modeling procedure. The second demand is the improvement of the description of the nonideality of the solid phase by using reliable equations or predictive models as a tool for the design of mixtures with 50 specific behaviors. The third is the evaluation of the modeling of systems comprising the peritectic reaction whose efforts are too incipient in the literature. The forth is deepening the understanding of the solid phases, with experimental and modeling tools in order to describe its behavior according to the 55 well known thermodynamic theories. The better the description of the SLE behavior of fatty systems the easiest the development or the optimization of fatty-based products and processes will be. New alternatives can be thus found to overcome industrial problems, opening pathways for new academic studies.

\section{${ }_{60}$ Acknowledgements}

The authors are grateful to the national funding agencies FAPESP (2012/05027-1, 2008/56258-8), CNPq (304495/2010-7, 483340/2012-0, 406856/2013-3) and CAPES (BEX-13716/12-3) for the financial support.

\section{${ }_{65}$ Notes and references}

${ }^{a}$ Laboratory of Extraction, Applied Thermodynamics and Equilibrium, School of Food Engineering, University of Campinas, R. Monteiro Lobato 80, 13083-862, Campinas, São Paulo, Brazil., Fax + 551935214027

Tel + 55193521 4037; E-mail tomze@fea.unicamp.br

$70{ }^{b}$ School of Applied Sciences, University of Campinas, R. Pedro Zaccaria, 1300, 13484-350, Limeira, São Paulo, Brazil. Fax +55 193701 6680;

Tel+551937016673; E-mail mariana.costa@fca.unicamp.br

${ }^{c}$ CICECO, Chemistry Department, University of Aveiro, 3810-193, Aveiro, Portugal. Fax + 351234401 470; Tel + 351234401 507; E75 mail jcoutinho@ua.pt

1. F.A.O., OECD-FAO Agricultural Outlook 2013, http://www.fao.org, Accessed 09/01/2013, 2013.

2. S. Octave and D. Thomas, Biochimie, 2009, 91, 659.

80 3. J. H. Clark, V. Budarin, F. E. I. Deswarte, J. J. E. Hardy, F. M. Kerton, A. J. Hunt, R. Luque, D. J. Macquarrie, K. Milkowski, A. Rodriguez, O. Samuel, S. J. Tavener, R. J. White and A. J. Wilson, Green Chem., 2006, 8, 853.

4. L. H. Wesdorp, PhD, Delft University of Technology, 1990.

85 5. C. Himawan, V. M. Starov and A. G. F. Stapley, Adv. Colloid Interfac., 2006, 122, 3.

6. K. W. Won, Fluid Phase Equilibr., 1993, 82, 261.

7. R. E. Timms, Prog. Lipid Res., 1984, 23, 1.

8. G. J. Maximo, N. D. D. Carareto, M. C. Costa, A. O. dos Santos, L. $90 \quad$ P. Cardoso, M. A. Krähenbühl and A. J. A. Meirelles, Fluid Phase Equilibr., 2014, 366, 88.

9. M. C. Costa, M. Sardo, M. P. Rolemberg, P. Ribeiro-Claro, A. J. A. Meirelles, J. A. P. Coutinho and M. A. Krähenbühl, Chem. Phys. Lipids, 2009, 157, 40.

95 10. F. Shahidi, Bailey's Industrial Oil and Fat Products, Wiley Interscience, 2005.

11. C. E. C. Rodrigues, R. Antoniassi and A. J. A. Meirelles, J. Chem. Eng. Data, 2003, 48, 367.

12. M. Lanza, G. Sanaiotti, E. A. C. Batista, R. J. Poppi and A. J. A. Meirelles, J. Chem. Eng. Data, 2009, 54, 1850.

13. C. E. C. Rodrigues, F. A. Silva, A. Marsaioli and A. J. A. Meirelles, J. Chem. Eng. Data, 2005, 50, 517.

14. C. E. C. Rodrigues, É. C. D. Reipert, A. F. de Souza, P. A. P. Filho and A. J. A. Meirelles, Fluid Phase Equilibr., 2005, 238, 193.

105 15. C. A. S. da Silva, G. Sanaiotti, M. Lanza, A. J. A. Meirelles and E. A. C. Batista, J. Chem. Eng. Data, 2010, 55, 2416.

16. J. Bezard, M. Bugaut and G. Clement, J. Am. Oil Chem. Soc., 1971, 48, 134.

17. R. C. Basso, F. H. Miyake, A. J. A. Meirelles and E. A. C. Batista, 110 Fuel, 117, 590.

18. J. A. Kent, Kent and Riegel's Handbook of Industrial Chemistry and Biotechnology, Springer Science + Business Media, New York, 2007.

19. I. Dalmolin, M. A. Mazutti, E. A. C. Batista, M. A. A. Meireles and J. V. Oliveira, J. Chem. Thermodyn., 2010, 42, 797.

115 20. S. Silva, K. Sampaio, T. Taham, S. Rocco, R. Ceriani and A. A. Meirelles, J. Am. Oil Chem. Soc., 2009, 86, 611.

21. J. R. O. Lima, R. B. da Silva, E. Miranda de Moura and C. V. Rodarte de Moura, Fuel, 2008, 87, 1718.

22. M. S. Cuevas, C. E. C. Rodrigues and A. J. A. Meirelles, J. Food 120 Eng., 2009, 95, 291. 
23. S. M. Silva, K. A. Sampaio, R. Ceriani, R. Verhé, C. Stevens, W. De Greyt and A. J. A. Meirelles, J. Food Eng., 2013, 118, 341

24. R. Ceriani and A. A. Meirelles, J. Am. Oil Chem. Soc., 2004, 81, 305.

25. K. M. Phillips, D. M. Ruggio, J. I. Toivo, M. A. Swank and A. H. Simpkins, Journal of Food Composition and Analysis, 2002, 15, 123.

26. P. T. Gee, Eur. J. Lipid Sci. Tech., 2007, 109, 373.

27. K. Smith, K. Bhaggan, G. Talbot and K. Malssen, J. Am. Oil Chem. Soc., 2011, 88, 1085.

28. A. G. Marangoni, N. Acevedo, F. Maleky, E. Co, F. Peyronel, G. Mazzanti, B. Quinn and D. Pink, Soft Matter, 2012, 8, 1275.

29. U. Kreutzer, J. Am. Oil Chem. Soc., 1984, 61, 343.

30. M. H. Gordon, in Oils and fat authentication, ed. M. Jee, Oxford, 2002, pp. 143.

31. R. W. Johnson and E. Fritz, Fatty Acids in Industry Processes, Properties, Derivatives, Applications, Marcel Dekker, Nova York, 1989.

32. H. Maag, J. Am. Oil Chem. Soc., 1984, 61, 259.

33. R. D. Farris, J. Am. Oil Chem. Soc., 1979, 56, 770A.

34. M. B. Dantas, M. Conceição, V. J. Fernandes Jr, N. Santos, R.

20 Rosenhaim, A. B. Marques, I. G. Santos and A. G. Souza, J. Therm. Anal. Calorim., 2007, 87, 835.

35. G. Knothe, Fuel Process. Technol., 2005, 86, 1059.

36. G. Knothe, Energ. Fuels, 2008, 22, 1358.

37. L. Ventolà, M. Ramírez, T. Calvet, X. Solans, M. A. Cuevas-Diarte, P. Negrier, D. Mondieig, J. C. van Miltenburg and H. A. J. Oonk, Chem. Mater., 2002, 14, 508.

38. M. Santos, G. C. Roux and V. Gerbaud, J. Am. Oil Chem. Soc., 2011, 88, 223.

39. M. C. Costa, L. A. D. Boros, J. A. P. Coutinho, M. A. Krähenbühl and A. J. A. Meirelles, Energ. Fuels, 2011, 25, 3244.

40. M. C. Costa, M. Sardo, M. P. Rolemberg, J. A. P. Coutinho, A. J. A. Meirelles, P. Ribeiro-Claro and M. A. Krähenbühl, Chem. Phys. Lipids, 2009, 160, 85.

41. E. Müller and H. Stage, Experimentelle vermessung von dampf-

35 flüssigkeits-phasengleichgewichten, Springer, Berlin, 1961.

42. B. J. Grondal and D. A. Rogers, Oil \& Soap, 1944, 21, 303.

43. F. Francis, F. J. E. Collins and S. H. Piper, Proc. Roy. Soc. A., 1937, 158, 691.

44. A. E. Bailey, Melting and solidification of fats, Interscience publishers, New York, 1950.

45. IUPAC, Compendium of Chemical Terminology, Blackwell Scientific Publications, Oxford, 1997.

46. E. Deffense, J. Am. Oil Chem. Soc., 1993, 70, 1193.

47. A. G. Marangoni and S. S. Narine, Food Res. Int., 2002, 35, 957.

45 48. S. S. Narine and A. G. Marangoni, Food Res. Int., 1999, 32, 227.

49. N. D. D. Carareto, M. C. Costa, M. P. Rolemberg, M. A. Krähenbühl and A. J. A. Meirelles, Fluid Phase Equilibr., 2011, 303, 191.

50. M. C. Costa, L. A. D. Boros, J. A. Souza, M. P. Rolemberg, M. A. Krähenbühl and A. J. A. Meirelles, J. Chem. Eng. Data, 2011, 56, 3277.

51. G. J. Maximo, M. C. Costa and A. J. A. Meirelles, Braz. J. Chem. Eng., 2013, 30, 33.

52. T. Inoue, Y. Hisatsugu, M. Suzuki, Z. Wang and L. Zheng, Chem. Phys. Lipids, 2004, 132, 225

55 53. G. G. Chernik, Adv. Colloid Interfac., 1995, 61, 65.

54. M. C. Costa, M. P. Rolemberg, A. J. A. Meirelles, J. A. P. Coutinho and M. A. Krähenbühl, Thermochim. Acta, 2009, 496, 30.

55. M. C. Costa, M. P. Rolemberg, L. A. D. Boros, M. A. Krähenbühl, M. G. Oliveira and A. J. A. Meirelles, J. Chem. Eng. Data, 2007, 52, 30.

56. M. C. Costa, L. A. D. Boros, M. L. S. Batista, J. A. P. Coutinho, M. A. Krähenbühl and A. J. A. Meirelles, Fuel, 2012, 91, 177.

57. L. Boros, M. L. S. Batista, R. V. Vaz, B. R. Figueiredo, V. F. S. Fernandes, M. C. Costa, M. A. Krähenbühl, A. J. A. Meirelles and J. A. P. Coutinho, Energ. Fuels, 2009, 23, 4625.

58. M. C. Costa, M. P. Rolemberg, L. A. D. Boros, M. A. Krähenbühl, M. G. de Oliveira and A. J. A. Meirelles, J. Chem. Eng. Data, 2007, $\mathbf{5 2}, 30$.

59. E. S. Lutton and F. R. Hugenberg, J. Chem. Eng. Data, 1962, 7, 208. 70 60. J. C. Smith, J. Chem. Soc., 1931, DOI: 10.1039/JR9310000802, 802.

61. M. P. Rolemberg, PhD, Universidade Estadual de Campinas, 2002.
62. T. Inoue, Y. Hisatsugu, R. Ishikawa and M. Suzuki, Chem. Phys. Lipids, 2004, 127, 161.

63. H. Imahara, E. Minami and S. Saka, Fuel, 2006, 85, 1666.

75 64. C. A. Lockemann and E. U. Schluender, J. Chem. Eng. Data, 1993, 38, 432 .

65. K. Nishimura, K. Maeda, H. Kuramochi, K. Nakagawa, Y. Asakuma, K. Fukui, M. Osako and S.-i. Sakai, J. Chem. Eng. Data, 2011, 56, 1613.

80 66. T. Inoue, Y. Hisatsugu, R. Yamamoto and M. Suzuki, Chem. Phys. Lipids, 2004, 127, 143.

67. N. D. D. Carareto, A. O. dos Santos, M. P. Rolemberg, L. P. Cardoso, M. C. Costa and A. J. A. Meirelles, Thermochim. Acta, 2014, (in press) [doi: 10.1016/j.tca.2014.05.022].

${ }_{85}$ 68. N. D. D. Carareto, Master, Universidade Estadual de Campinas, 2010.

69. D. G. Kolp and E. S. Lutton, J. Chem. Eng. Data, 1962, 7, 207.

70. M. C. Costa, L. A. D. Boros, M. P. Rolemberg, M. A. Krähenbühl and A. J. A. Meirelles, J. Chem. Eng. Data, 2010, 55, 974.

90 71. M. C. Costa, Post-Doctoral University of Campinas, 2011.

72. J. Zeng, Z. Cao, D. Yang, F. Xu, L. Sun, L. Zhang and X. Zhang, J. Therm. Anal. Calorim., 2009, 95, 501.

73. G. J. Maximo, PhD, University of Campinas, 2014.

74. F. G. Gandolfo, A. Bot and E. Flöter, Thermochim. Acta, 2003, 404, 9.

75. S. Ueno, T. Suetake, J. Yano, M. Suzuki and K. Sato, Chem. Phys. Lipids, 1994, 72, 27.

76. A. Aro, M. Jauhiainen, R. Partanen, I. Salminen and M. Mutanen, Am. J. Clin. Nutr., 1997, 65, 1419.

100 77. U. Domańska, J Solution Chem., 1989, 18, 173.

78. M. Benziane, K. Khimeche, A. Dahmani, S. Nezar and D. Trache, $J$. Therm. Anal. Calorim., 2013, 112, 229.

79. U. Domańska, P. Morawski and M. Piekarska, J. Chem. Eng. Data, 2009, 54, 1271.

105 80. S. Benessam, K. Khimeche, F. Djellouli, M. Benziane and A. Dahmani, J. Therm. Anal. Calorim., 2013, 112, 317.

81. G. G. Chernik, Curr. Opin. Colloid In., 1999, 4, 381.

82. R. Koynova and M. Caffrey, Chem. Phys. Lipids, 2002, 115, 107.

83. G. J. Maximo, R. J. B. N. Santos, J. A. Lopes da Silva, M. C. Costa,

110 A. J. A. Meirelles and J. A. P. Coutinho, ACS Sustainable Chem. Eng., 2014, 4, 672.

84. H. Qiu and M. Caffrey, Biomaterials, 2000, 21, 223.

85. R. L. de Souza, E. L. P. de Faria, R. T. Figueiredo, L. d. S. Freitas, M. Iglesias, S. Mattedi, G. M. Zanin, O. A. A. dos Santos, J. A. P.

115 Coutinho, A. S. Lima and C. M. F. Soares, Enzyme Microb. Tech., 2013, 52, 141.

86. A. Yaghmur and O. Glatter, Adv. Colloid Interfac., 2009, 147-148, 333.

87. I. Dierking, Textures of liquid crystals, Wiley-VCH Weinheim, 2003.

120 88. M. C. Costa, M. P. Rolemberg, A. O. dos Santos, L. P. Cardoso, M. A. Kraehenbuehl and A. J. A. Meirelles, J. Chem. Eng. Data, 2010, $\mathbf{5 5}, 5078$.

89. R. E. Timms, Eur. J. Lipid Sci. Tech., 2005, 107, 48.

90. H. M. Schaink, K. F. van Malssen, S. Morgado-Alves, D. Kalnin and E. van der Linden, Food Res. Int., 2007, 40, 1185 .

91. F. G. Gandolfo, A. Bot and E. Floter, J. Am. Oil Chem. Soc., 2004, 81, 1 .

92. G. J. Suppes, M. J. Goff and S. Lopes, Chem. Eng. Sci., 2003, 58, 1751.

130 93. L. Shilei, Z. Neng and G. H. Feng, Energ Buildings, 2006, 38, 708.

94. J. J. Zhang, J. L. Zhang, S. M. He, K. Z. Wu and X. D. Liu, Thermochim. Acta, 2001, 369, 157.

95. J. V. Gerpen, Fuel Process. Technol., 2005, 86, 1097.

96. J. A. P. Coutinho, M. Gonçalves, M. J. Pratas, M. L. S. Batista, V. F.

135 S. Fernandes, J. Pauly and J. L. Daridon, Energ. Fuels, 2010, 24, 2667.

97. J. Daniel and R. Rajasekharan, J. Am. Oil Chem. Soc., 2003, 80, 417.

98. D. Feldman, M. M. Shapiro, D. Banu and C. J. Fuks, Sol. Energ. Mater., 1989, 18, 201.

140 99. R. C. Reid, J. M. Prausnitz and B. E. Pouling, The properties of gases and liquids, McGraw-Hill, New York, 1987. 
100.J. Gmehling, B. Kolbe, M. Kleiber and J. Rarey, Chemical Thermodynamics for Process Simulation, Wiley-VHC, Weinheim, 2012.

101.D. S. Abrams and J. M. Prausnitz, Aiche J., 1975, 21, 116.

5 102.A. Fredenslund, R. L. Jones and J. M. Prausnitz, Aiche J., 1975, 21, 1086 .

103.J. G. Gmehling, T. F. Anderson and J. M. Prausnitz, Ind. Eng. Chem. Fund., 1978, 17, 269.

104.J. A. P. Coutinho, Ind. Eng. Chem. Res., 1998, 37, 4870.

10 


\section{Trends and demands in solid-liquid equilibrium of lipidic mixtures}

Guilherme J. Maximo, ${ }^{a, c}$ Mariana C. Costa, ${ }^{b}$ João A. P. Coutinho, ${ }^{c}$ and Antonio J. A. Meirelles ${ }^{a}$

a Laboratory of Extraction, Applied Thermodynamics and Equilibrium, School of Food Engineering, University of Campinas, R. Monteiro Lobato 80, 13083-862, Campinas, São Paulo, Brazil., Fax: + 5519 35214027 Tel: + 55193521 4037; E-mail: tomze@fea.unicamp.br

${ }^{\mathrm{b}}$ School of Applied Sciences, University of Campinas, R. Pedro Zaccaria, 1300, 13484-350, Limeira, São Paulo, Brazil. Fax: +55 193701 6680; Tel:+55 193701 6673; E-mail: mariana.costa@fca.unicamp.br ${ }^{\mathrm{c}}$ CICECO, Chemistry Department, University of Aveiro, 3810-193, Aveiro, Portugal. Fax: + 351234401 470; Tel: + 351234401 507; E-mail: jcoutinho@ua.pt

\section{Table of contents entry}

The increasing importance of the oil chemistry in industry and academic research has been demanding a deeper understanding on solid-liquid equilibrium of lipidic systems that is still far from complete.

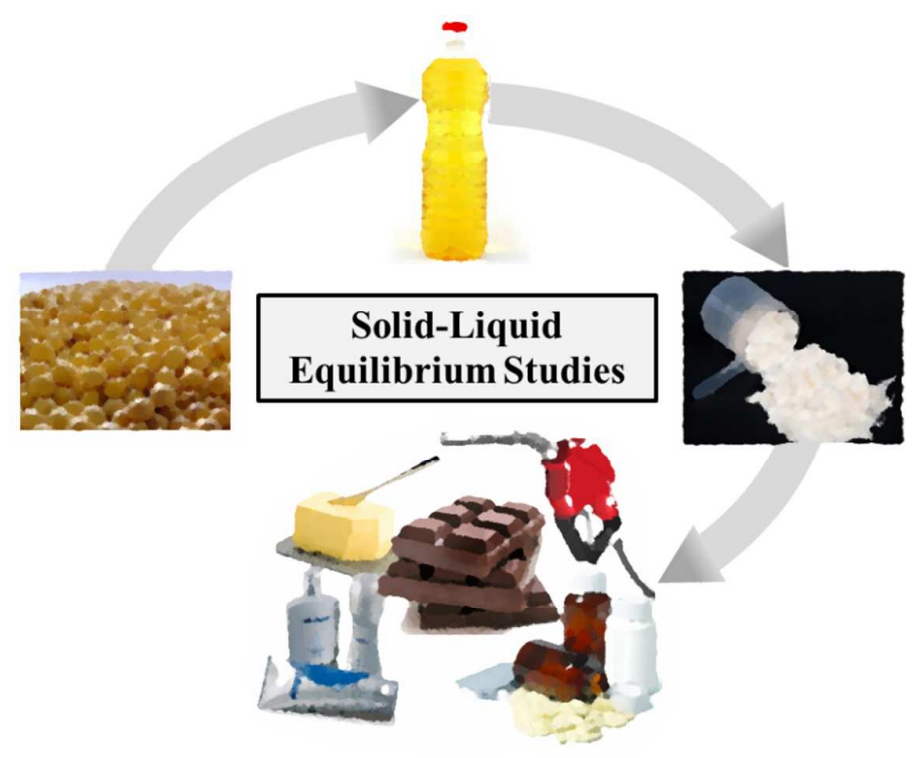

